\title{
Genetic Deficiency of Short-Chain Acyl-Coenzyme A Dehydrogenase in Cultured Fibroblasts from a Patient with Muscle Carnitine Deficiency and Severe Skeletal Muscle Weakness
}

\author{
Paul M. Coates, Daniel E. Hale, Gaetano Finocchiaro, “ Kay Tanaka, ${ }^{\star}$ and Susan C. Winter ${ }^{*}$ \\ Divisions of Genetics and Endocrinology/Diabetes, The Children's Hospital of Philadelphia, and Department of Pediatrics, University \\ of Pennsylvania School of Medicine, Philadelphia, Pennsylvania 19104; Department of Human Genetics, ${ }^{*}$ Yale University School of \\ Medicine, New Haven, Connecticut 06510; and Division of Medical Genetics, ${ }^{\ddagger}$ Valley Children’s Hospital, Fresno, California 93703
}

\begin{abstract}
Genetic deficiency of short-chain acyl-coenzyme A (CoA) dehydrogenase activity was demonstrated in cultured fibroblasts from a 2-yr-old female whose early postnatal life was complicated by poor feeding, emesis, and failure to thrive. She demonstrated progressive skeletal muscle weakness and developmental delay. Her plasma total carnitine level $(35 \mathrm{nmol} / \mathrm{ml})$ was low-normal, but was esterified to an abnormal degree (55\% vs. controls of $<10 \%$ ). Her skeletal muscle total carnitine level was low $(7.6 \mathrm{nmol} / \mathrm{mg}$ protein vs. controls of $14 \pm 2$ $\mathrm{nmol} / \mathrm{mg}$ protein) and was $\mathbf{7 5 \%}$ esterified. Mild lipid deposition was noted in type I muscle fibers. Fibroblasts from this patient had $50 \%$ of control levels of acyl-CoA dehydrogenase activity towards butyryl-CoA as substrate at a concentration of $50 \mu \mathrm{M}$ in a fluorometric assay based on the reduction of electron transfer flavoprotein. All of this residual activity was inhibited by an antibody against medium-chain acyl-CoA dehydrogenase. These data demonstrated that medium-chain acylCoA dehydrogenase accounted for $50 \%$ of the activity towards the short-chain substrate, butyryl-CoA, under these conditions, but that antibody against that enzyme could be used to unmask the specific and virtually complete deficiency of shortchain acyl-CoA dehydrogenase in this patient. Fibroblasts from her parents had intermediate levels of activity towards butyryl-CoA, consistent with the autosomal recessive inheritance of this metabolic defect.
\end{abstract}

\section{Introduction}

Within the last few years, inherited disorders of enzymes involved in the $\beta$-oxidation of fatty acids have been described by a number of investigators. These enzymatic defects: carnitine palmityltransferase deficiency (1), long-chain acyl-coenzyme A $(\mathrm{COA})^{1}$ dehydrogenase (LCAD) deficiency (2), medium-

Address all correspondence to Dr. P. M. Coates, Division of Genetics, The Children's Hospital of Philadelphia, 34th St. and Civic Center Blvd., Philadelphia, PA 19104.

Received for publication 7 April 1987 and in revised form 17 August 1987.

1. Abbreviations used in this paper: CoA, coenzyme A; ETF, electron transfer flavoprotein; LCAD, long-chain acyl-CoA dehydrogenase; MCAD, medium-chain acyl-CoA dehydrogenase; SCAD, short-chain acyl-CoA dehydrogenase.

J. Clin. Invest.

(C) The American Society for Clinical Investigation, Inc. $0021-9738 / 88 / 01 / 0171 / 05 \quad \$ 2.00$

Volume 81, January $1988,171-175$ chain acyl-CoA dehydrogenase (MCAD) deficiency (3-13), electron transfer flavoprotein (ETF) deficiency (14-16), and ETF dehydrogenase deficiency (14) all have been demonstrated in cultured skin fibroblasts, although extracts of other tissues have been used to diagnose specific enzyme defects in this metabolic pathway, including skeletal muscle (1), liver (4, 9 ), and peripheral mononuclear leukocytes $(2,6)$.

Under physiological conditions, fatty acids are imported into mitochondria through the action of carnitine palmityltransferase, and then they are oxidized and shortened by a sequence of enzymes in the $\beta$-oxidation spiral. The first reaction of each $\beta$-oxidation spiral is catalyzed by an acyl-CoA dehydrogenase. Three acyl-CoA dehydrogenases are known to act on acyl-CoA esters of different chain length: LCAD, MCAD, and SCAD $(17,18)$. These acyl-CoA dehydrogenases are all homotetrameric flavoproteins, and require ETF as an obligatory electron acceptor. Their names indicate the approximate range of chain length of their preferred substrates, but overlap in their substrate specificities has been observed $(17,18)$.

The most common genetic disorder of this pathway, MCAD deficiency, has now been confirmed by enzyme measurements or strongly suspected by urinary metabolite excretion patterns in at least 65 patients (3-13; Hale, D. E., and P. M. Coates, unpublished observations).

Patients with LCAD deficiency have some clinical and laboratory findings similar to those with MCAD deficiency, and in addition, may have severe skeletal muscle weakness and cardiomyopathy $(2,19)$. Both LCAD deficiency and MCAD deficiency are inherited in an autosomal recessive manner; fibroblasts and leukocytes from parents of affected children have half-normal levels of the affected enzyme $(2,6)$.

Recently, short-chain acyl-CoA dehydrogenase (SCAD) deficiency has been identified in four patients (20-22). In one of these, Turnbull et al. (20) identified SCAD deficiency in skeletal muscle of a middle-aged woman with progressive muscle weakness, lipid storage myopathy, and muscle carnitine deficiency. A patient with similar findings has been reported in abstract form by DiDonato et al. (21). The other two patients (22) were recognized as infants with metabolic acidosis and ethylmalonic aciduria; fibroblasts from these two patients demonstrated a deficiency of SCAD, measured using butyryl-CoA as substrate. Family studies were not performed in any of the four cases, however, making it impossible to determine if their enzyme deficiency was due to a structural gene defect or a secondary phenomenon.

The present report describes the genetic deficiency of SCAD, demonstrated in fibroblasts from a patient with severe skeletal muscle weakness, developmental delay, and muscle carnitine deficiency. Fibroblasts from her parents had inter- 
mediate levels of SCAD activity, consistent with autosomal recessive inheritance of this disorder. The interpretation of the results initially was complicated by the significant residual butyryl-CoA dehydrogenating activity in patient cells, but was resolved by the use of polyclonal monospecific antibodies against MCAD and SCAD, which could differentiate between the contributions of these two enzymes to the dehydrogenation of butyryl-CoA.

\section{Methods}

\section{Case report}

The proband, G-1, a female infant, was the $3.6-\mathrm{kg}$ appropriate for gestational age product of an uncomplicated pregnancy, born to a 20-yr-old gravida 2, para 1, Caucasian female of French and Irish ancestry and her 23-yr-old Hispanic husband. There was no known consanguinity. Labor was induced at 43 wk and delivery was vaginal vertex. She fed poorly in the newborn period and vomited most feeds. She was admitted at 2 mo of age for failure to thrive. A barium swallow revealed gastroesophageal reflux. During the first year, she exhibited poor weight gain, developmental delay, progressive skeletal muscle weakness, hypotonia, and microcephaly. The mother reported that the baby had frequent episodes of staring; however, both electroencephalogram and computerized tomographic scan were normal.

At 6 mo of age, she had no head control, and was unable to sit or bear weight on her legs. Head circumference was $39 \mathrm{~cm}$ (below the $3 \mathrm{rd}$ percentile); height, $65 \mathrm{~cm}$ (50th percentile); and weight, $5.4 \mathrm{~kg}$ (below the $3 \mathrm{rd}$ percentile). The liver edge was firm and palpable at $3 \mathrm{~cm}$. Urine organic acid screening showed a mild elevation of dicarboxylic acids, a mild generalized amino aciduria and modest elevation of $\beta$-hydroxybutyrate; it was otherwise unremarkable.

Because of the progressive muscle weakness and onset of ptosis, the infant was hospitalized at 8 mo of age for evaluation. A right quadriceps muscle biopsy was performed. Minor generalized accentuation of intrafiber lipid deposits in type I fibers was noted; otherwise, the findings were unremarkable. The plasma level of creatine phosphokinase was normal (68 IU/liter), and there was a mild elevation of serum glutamic-pyruvic transaminase ( $72 \mathrm{IU} /$ liter). The total carnitine level in muscle was $7.6 \mathrm{nmol} / \mathrm{mg}$ noncollagen protein (control, $14 \pm 2$ $\mathrm{nmol} / \mathrm{mg}$ noncollagen protein), and was $75 \%$ esterified (control, $<40 \%$ ). The child has never had any episodes of hypoglycemia.

At $11 \mathrm{mo}$ of age, an echocardiogram was normal. Plasma total carnitine was $35 \mu \mathrm{mol} / \mathrm{liter}$ (control range, $40-60 \mu \mathrm{mol} / \mathrm{liter}$ ), and was $55 \%$ esterified (control, $<10 \%$ ). She was begun on a fat-restricted diet (16\% of total calories) supplemented with L-carnitine (Sigma-Tau S.P.A., Pomezia, Rome, Italy) at $300 \mathrm{mg} / \mathrm{kg}$ per d. The patient's response to therapy generally was poor; she failed to gain weight and remained hypotonic. Persistent diarrhea required lowering her L-carnitine dosage to $100 \mathrm{mg} / \mathrm{kg}$ per $\mathrm{d}$.

Developmental testing at 21 mo showed a gross motor level of 5 mo, a fine motor level of 8-9 mo, a cognitive development level of 5-9 mo, and a language-social level of 3-4 mo. Increasing difficulty with oral intake necessitated insertion of a gastrostomy tube at 23 mo. Despite intermittent gastrostomy tube blockage, she has shown significant weight gain and overall improvement in strength at $32 \mathrm{mo}$.

Chemicals. Butyryl-CoA, octanoyl-CoA, and palmityl-CoA were obtained from Pharmacia Fine Chemicals (Piscataway, NJ). All other reagents were obtained from Sigma Chemical Co. (St. Louis, MO).

Fibroblasts. Cultured skin fibroblasts were obtained from the patient, her parents, 90 controls ranging in age from $6 \mathrm{~d}$ to $13 \mathrm{yr}, 35$ patients with MCAD deficiency ranging in age from $3 \mathrm{mo}$ to $17 \mathrm{yr}$, and 14 obligate heterozygotes for MCAD deficiency ranging in age from 21 to $36 \mathrm{yr}$. 16 of the MCAD-deficient patients $(6,23,24)$ have been described previously. Fibroblasts were grown and prepared for enzyme assay as previously described $(2,6)$.

Acyl-CoA dehydrogenase assays. Acyl-CoA dehydrogenase activities were measured using an ETF reduction assay (25). Details of this assay are presented elsewhere $(2,6)$. Briefly, fibroblasts were sonicated and centrifuged at $40,000 \mathrm{~g}$ for $30 \mathrm{~min}$, and acyl-CoA dehydrogenase activities were measured in the supernatant fraction. Butyryl-CoA, octanoyl-CoA, and palmityl-CoA were used as substrates at a final concentration of $50 \mu \mathrm{M}$, for the SCAD, MCAD, and LCAD activities, respectively. ETF, purified from pig liver as previously described $(2,6)$, was used as the electron acceptor at a final concentration of $2 \mu \mathrm{M}$ under anaerobic conditions. Protein content of fibroblast supernatants was measured by the method of Lowry et al. (26). Results of enzyme assay were expressed as nanomoles ETF reduced/minute per milligram protein.

Antibodies to rat liver medium-chain and short-chain acyl-CoA dehydrogenases. Antibodies were raised in rabbits against purified rat liver MCAD and SCAD, as previously described $(17,23)$. These antibodies were monospecific; they did not cross-react with nor inhibit the activity of any rat liver acyl-CoA dehydrogenase other than the one used as antigen (17). They did, however, cross-react specifically with the corresponding human fibroblast $\operatorname{MCAD}$ and $\operatorname{SCAD}(18,23,27)$. When used to inhibit acyl-CoA dehydrogenase activities, they were preincubated with cell extracts for $1 \mathrm{~h}$ at room temperature before assay. Because the acyl-CoA dehydrogenase enzymes lose $\sim 25 \%$ of their activity per hour under these conditions without the addition of antibody (28), a control was included in which the same cell extract was incubated at room temperature for $1 \mathrm{~h}$ with nonimmune serum.

\section{Results}

SCAD activity has been measured in this and in previous studies using butyryl-CoA as substrate. As shown in Table I, cells from patient G-1 had 50\% of the mean control enzyme activity using this substrate ( 1.09 vs. $2.18 \pm 0.25 \mathrm{nmol}$ ETF reduced/min per $\mathrm{mg}$ protein, $P<0.05$ ). This result has been confirmed repeatedly. In patient G-1 cells, MCAD and LCAD activities measured using octanoyl-CoA and palmityl-CoA, respectively, were well within the control range (4.01 vs. $4.14 \pm 0.38 \mathrm{nmol} \mathrm{ETF}$ reduced $/ \mathrm{min}$ per $\mathrm{mg}$ protein, $P>0.1$ and 2.35 vs. $2.20 \pm 0.21 \mathrm{nmol}$ ETF reduced/min per $\mathrm{mg}$ protein, $P>0.1$, respectively).

Three pieces of evidence suggest that this patient has a specific genetic deficiency of SCAD. First, cells from patients with MCAD deficiency have been shown previously (6) to have $\sim 50 \%$ of cớntrol activity towards butyryl-CoA $(0.95 \pm 0.16$ vs. $2.18 \pm 0.25 \mathrm{nmol}$ ETF reduced/min per $\mathrm{mg}$ protein, $P<0.05$ ), in addition to the virtually complete loss of

Table I. Acyl-CoA Dehydrogenase Activities in Fibroblasts

\begin{tabular}{|c|c|c|c|}
\hline \multirow[b]{2}{*}{ Subjects } & \multicolumn{3}{|c|}{ Acyl-CoA dehydrogenase activity measured using } \\
\hline & Palmityl-CoA & Octanoyl-CoA & Butyryl-CoA \\
\hline & \multicolumn{3}{|c|}{ nmol ETF reduced/min per $\mathrm{mg}$ protein $\pm S D$} \\
\hline Patient G-1 $(1)^{*}$ & 2.35 & 4.01 & $1.09^{\ddagger}$ \\
\hline Parents (2) & NT & $4.09 ; 4.37$ & $1.61 ; 1.57$ \\
\hline Controls $(90)$ & $2.20 \pm 0.21$ & $4.14 \pm 0.38$ & $2.18 \pm 0.25$ \\
\hline MCAD deficient (35) & $2.12 \pm 0.25$ & $0.25 \pm 0.11^{\ddagger}$ & $0.95 \pm 0.16^{\ddagger}$ \\
\hline $\begin{array}{l}\text { MCAD heterozygote } \\
\text { (14) }\end{array}$ & $2.21 \pm 0.27$ & $2.01 \pm 0.41^{\ddagger}$ & $1.56 \pm 0.16^{\ddagger}$ \\
\hline
\end{tabular}

* The number of individual patient cultures is given in parentheses. For all cultures, results were obtained at least in triplicate. NT, not tested.

₹ Significantly different from control cells assayed with the same substrate, $P<0.05$. 
activity towards octanoyl-CoA $(0.25 \pm 0.11$ vs. $4.14 \pm 0.38 \mathrm{nmol}$ ETF reduced/min per $\mathrm{mg}$ protein, $P<0.01$ ), when assayed using the same method. This suggests that a substantial portion of the activity towards the short-chain substrate under the assay conditions described, with ETF as the electron acceptor, is due to MCAD. Thus, if $50 \%$ of the measured activity towards buttyryl-CoA can be accounted for by MCAD, then the SCAD enzyme will contribute, at most, $50 \%$ of the apparent enzyme activity when assayed with this substrate.

Second, fibroblasts from both parents of this patient with SCAD deficiency had $\sim 75 \%$ of control enzyme activity using butyryl-CoA as substrate (Table I), halfway between that found for the patient and for controls and exactly what one would predict for an enzyme activity in cells from heterozygotes for an autosomal recessive disorder. Cells from the parents had acyl-CoA dehydrogenase activities towards octanoyl$\mathrm{CoA}$ and palmityl-CoA that were within the control range. The combination of $75 \%$ residual activity towards butyrylCoA and normal activity towards octanoyl-CoA distinguishes heterozygotes for SCAD deficiency from heterozygotes for MCAD deficiency, who also had $\sim 75 \%$ of control activity towards butyryl-CoA, but whose activity towards octanoylCoA was only $50 \%$ of control levels (6).

Third, we have shown elsewhere (Hale, D. E., G. Finocchiaro, P. M. Coates, and K. Tanaka, manuscript in preparation) that an antibody raised against MCAD (anti-MCAD) inhibited virtually all of the enzyme activity towards octanoylCoA and inhibited $50 \%$ of the enzyme activity towards butyryl-CoA in control cells; it was without effect on the residual enzyme activity towards butyryl-CoA in MCAD-deficient cells.

In the present study, an antibody raised against SCAD (anti-SCAD) was found to inhibit 50\% of the enzyme activity towards butyryl-CoA in control cells and to completely inhibit the residual activity towards butyryl-CoA in MCAD-deficient cells (Table II). The residual activity towards butyryl-CoA as substrate in cells from G-1 was unaffected by anti-SCAD $(92 \%$ of activity present in cells treated with nonimmune IgG, $P$ $>0.1$ ), but it was almost completely inhibited by anti-MCAD ( $10 \%$ of activity present in cells treated with nonimmune IgG, $P<0.05)$. These data support the conclusion that proband G-1 has a specific SCAD deficiency and that the residual $51 \%$ of

Table II. Effect of Monospecific Antibodies against MediumChain Acyl-CoA Dehydrogenase (Anti-MCAD) and Short-Chain Acyl-CoA Dehydrogenase (Anti-SCAD) on Fibroblast Acyl-CoA Dehydrogenase Activity with Butyryl-CoA as Substrate

\begin{tabular}{llll}
\hline & \multicolumn{3}{l}{ Acyl-CoA dehydrogenase activity in the presence of } \\
\cline { 2 - 4 } Subjects $(n)$ & Nonimmune serum & Anti-MCAD serum & Anti-SCAD serum \\
\hline & nmol ETF reduced/min per mg protein $\pm S D$ & \\
& & & \\
Control (3) & $1.52 \pm 0.17(12)^{* \ddagger}$ & $0.69 \pm 0.10(11)$ & $0.69 \pm 0.09(12)$ \\
$\begin{array}{c}\text { MCAD } \\
\text { deficient (2) }\end{array}$ & $0.73 \pm 0.04(4)^{*}$ & $0.75 \pm 0.08(8)$ & $0.05 \pm 0.07(8)^{*}$ \\
$\begin{array}{c}\text { SCAD } \\
\text { deficient (1) }\end{array}$ & $0.78 \pm 0.07(3)^{*}$ & $0.08 ; 0.08(2)^{*}$ & $0.72 \pm 0.03(3)$ \\
\end{tabular}

* Significantly different from control cells assayed under the same conditions, $P<0.05$.

‡ The number of individual assays is shown in parentheses. enzyme activity towards butyryl-CoA is due to MCAD, as determined under the current assay conditions.

Finally, we have measured acyl-CoA dehydrogenase activities in fibroblasts from the patient described by Turnbull et al. (20) with short-chain acyl-CoA dehydrogenase deficiency demonstrated in skeletal muscle. Acyl-CoA dehydrogenase activities towards butyryl-CoA, octanoyl-CoA, and palmitylCoA were 2.12, 4.34, and $2.04 \mathrm{nmol}$ ETF reduced $/ \mathrm{min}$ per $\mathrm{mg}$ protein, respectively. We also measured these enzymes in fibroblasts from the patient described by Bennett et al. (28) with a defect in fibroblast short-chain fatty acid oxidation. AcylCoA dehydrogenase activities towards butyryl-CoA, octanoylCoA, and palmityl-CoA were 2.16, 4.37, and 1.93 nmol ETF reduced/min per $\mathrm{mg}$ protein, respectively. Neither patient had a SCAD deficiency that was evident in fibroblasts.

\section{Discussion}

Short-chain acyl-CoA dehydrogenase deficiency has been described recently in association with distinctly different clinical phenotypes. The patient described in the present report presented early in life with nonspecific vomiting, poor feeding, and failure to thrive. Her chronic problems were largely those of progressive skeletal muscle weakness and developmental delay. Her findings are very different from those of the two female infants with SCAD deficiency identified in cultured fibroblasts by Amendt et al. (22). They both presented in early infancy with poor feeding and lethargy, significant metabolic acidosis, and excreted a number of metabolites in urine, suggestive of a block in short-chain fatty acid oxidation. Their metabolite excretion pattern resembled that of a patient described by Bennett et al. (28), who had a defect in short-chain fatty acid oxidation. This latter patient, however, was demonstrated in the present report not to have SCAD deficiency; it is possible that another enzyme in $\beta$-oxidation is defective in her cells.

The patients described with muscle SCAD deficiency (20, 21) had significant skeletal muscle weakness, myoglobinuria, and muscle carnitine deficiency, with no findings referable to an abnormality in hepatic fatty acid metabolism. In some respects, these patients resembled others who had been reported previously with "muscle carnitine deficiency" (29). These patients $(20,21)$ appeared to have SCAD deficiency expressed in skeletal muscle; our results, confirmed by Amendt et al. (22), demonstrated that fibroblasts from the patient described by Turnbull et al. (20) had normal SCAD activity.

There are several possible explanations for the apparent tissue difference in the expression of SCAD deficiency in the patient reported by Turnbull et al. (20). One possible explanation is a mutation of a muscle-specific SCAD isozyme; this assumes that there are tissue-specific SCAD isozymes. Carroll et al. (30) recently used an electrophoretic analysis coupled with a histochemical staining method to demonstrated acylCoA dehydrogenases in crude extracts of human skeletal muscle mitochondria. MCAD and LCAD in skeletal muscle were identical to their counterparts in liver and heart. By contrast, SCAD was detected only in muscle, and not in heart or liver under these conditions. More recently, Finocchiaro et al. (18) purified SCAD, MCAD, and isovaleryl-CoA dehydrogenase to homogeneity from human liver. In general, these human liver acyl-CoA dehydrogenases were identical to their counterparts in human fibroblasts $(23,27)$ and placenta (Finocchiaro, G., M. Ito, and K. Tanaka, unpublished observations), and were 
very similar to the corresponding rat enzymes in their molecular, catalytic, and immunologic properties $(17,18)$. Current evidence, therefore, seems to suggest that a muscle-specific SCAD isozyme is unlikely, but at present, there are no direct data that conclusively exclude this possibility. It is possible that all tissues share the same SCAD gene, but that the mechanisms that regulate its expression may differ among them. Alternatively, the apparent SCAD deficiency in this patient's cells may be a secondary phenomenon, perhaps due to degeneration of muscle mitochondria for other reasons. Another possibility that may explain her enzyme abnormality is a riboflavin-responsive multiple acyl-CoA dehydrogenation defect (31). SCAD is relatively susceptible to riboflavin deficiency, at least in the rat $(32,33)$. This patient might be sufficiently riboflavin deficient to depress SCAD activity in muscle without affecting the activities of other acyl-CoA dehydrogenases; her cultured fibroblasts may have normal SCAD activity because the medium in which they are grown contains riboflavin.

The clinical and laboratory findings in patient G-1, which include chronic skeletal muscle weakness, developmental delay, and reduced muscle carnitine levels with an increased content of esterified carnitine, are different from those often found in patients with MCAD or LCAD deficiency: Many of the latter patients present during the first $18 \mathrm{mo}$ of life with a Reye Syndrome-like episode, in which fasting stress results in lethargy and vomiting, sometimes leading to coma and often associated with hypoglycemia, a failure of ketosis and secondary plasma and tissue carnitine deficiency (19). Only the rare patient with MCAD deficiency has been reported to have muscle weakness, whereas this has been a common finding among patients with LCAD deficiency.

Over the last several years, there has developed a simple strategy for defining patients with carnitine deficiency (29): those with low levels of carnitine in plasma, liver, and muscle have been identified as having "systemic carnitine deficiency," whereas those with low muscle carnitine levels, but normal plasma and liver carnitine, were said to have "muscle carnitine deficiency." In general, the latter disease is characterized by low muscle carnitine levels, progressive muscle weakness (of varying degree), and lipid accumulation in skeletal muscle fibers (also of varying degree). These patients usually have been identified at a much older age than G-1 (for example, the patient described by Turnbull et al. [20]), although a few have presented within the first several years of life. For some of them, the clinical course has been unrelenting and fatal in spite of carnitine therapy, whereas others have responded favorably to oral carnitine therapy (29). It is unknown whether any of these patients have SCAD deficiency, either expressed in muscle, as in Turnbull's patient, or perhaps generalized and expressed in fibroblasts, as in patient G-1. Together, however, these findings suggest that patients who have until now carried the diagnosis of muscle carnitine deficiency should be reevaluated to determine whether they have specific defects in $\beta$-oxidation, such as SCAD deficiency.

We can speculate that, by analogy with other known defects in $\beta$-oxidation, the failure to completely oxidize fatty acids in mitochondria would lead to the accumulation of acylCoA compounds, in this case butyryl-CoA, which are potentially cytotoxic. This may be particularly true for muscle, since fatty acids are a major substrate for oxidative metabolism in this tissue. Whereas the liver has adaptive mechanisms for handling these toxic intermediates (e.g., $\alpha$-carboxylation, gly- cine conjugation, acylcarnitine formation, and omega oxidation), it may be that skeletal muscle is less capable of removing acyl-CoA moieties by these alternative routes.

In the present report, the ETF reduction assay was used to measure the acyl-CoA dehydrogenase activities in fibroblasts from patient G-1 and from her parents. In the only other report of SCAD deficiency in fibroblasts, Amendt et al. (22) used a tritium-release assay and an ETF-linked dichlorophenolindophenol reduction assay to demonstrate reduced SCAD activity in their patients. Because the observed activity of MCAD towards butyryl-CoA as substrate is so high, both in our hands and as described by Amendt et al. (22), it was necessary to carefully distinguish the contributions of MCAD and SCAD towards butyryl-CoA by selective inhibition of each enzyme using antibodies of known specificity. Coupled with our previous data, it is evident that these monospecific antibodies are powerful tools with which to discern the substrate specificities of these enzymes.

Amendt et al. (22) found an interesting difference in the enzyme activities of their two patients with SCAD deficiency. One of them, Neonate I, had significantly reduced activity towards both butyryl-CoA and octanoyl-CoA; all of the residual activity towards both substrates could be inhibited by an anti-pig MCAD antibody. The reason for the substantially reduced activity towards octanoyl-CoA is unclear. The authors noted the possibility that this child's cells may have constitutively lowered activities of $\beta$-oxidation enzymes (LCAD, isovaleryl-CoA dehydrogenase, and ETF activities were all somewhat depressed compared with control); another possibility, which could not be pursued since cells from the parents were unavailable for study, is that Neonate $I$ is heterozygous for MCAD deficiency, in addition to having SCAD deficiency. Neonate II, on the other hand, appeared to have an isolated SCAD deficiency, very similar to that found in cells from our patient, G-1. Because we had the opportunity to study fibroblasts from the parents of patient G-1, we were able to demonstrate that their cells had intermediate levels of SCAD activity, consistent with heterozygosity for an autosomal disorder.

\section{Acknowledgments}

We thank Ms. Gwen Lech, Ms. Terry Fox, and Mr. James Wright for their expert technical assistance, and Ms. Jean Lewis and Ms. Regina Kobli for preparation of the manuscript. We thank Drs. D. M. Turnbull and M. J. Bennett for making available fibroblasts from their patients. The antibodies directed against rat short-chain and mediumchain acyl-CoA dehydrogenases were prepared by Dr. Yasuyuki Ikeda, Yale University Department of Human Genetics. We thank Dr. W. J. Rhead for sharing his data regarding the acyl-CoA dehydrogenase activities in cells from his patients, in advance of their publication.

This work was supported by grants from the National Institutes of Health (NS-17752, AM-01226, and DK-38154) and from the March of Dimes-Birth Defects Foundation (6-648 and 1-378).

\section{References}

1. DiMauro, S., and P. M. DiMauro. 1973. Muscle carnitine palmityltransferase deficiency and myoglobinuria. Science (Wash. DC). 182:929-931.

2. Hale, D. E., M. L. Batshaw, P. M. Coates, F. E. Frerman, S. I. Goodman, I. Singh, and C. A. Stanley. 1985. Long-chain acyl coenzyme A dehydrogenase deficiency: an inherited cause of nonketotic hypoglycemia. Pediatr. Res. 19:666-671.

3. Kolvraa, S., N. Gregersen, E. Christensen, and N. Hobolth. 
1982. In vitro fibroblast studies in a patient with $\mathrm{C}_{6}-\mathrm{C}_{10}$-dicarboxylic aciduria: evidence for a defect in general acyl-CoA dehydrogenase. Clin. Chim. Acta. 126:53-67.

4. Stanley, C. A., D. E. Hale, P. M. Coates, C. L. Hall, B. E. Corkey, W. Yang, R. I. Kelley, C. Gonzales, J. R. Williamson, and L. Baker. 1983. Medium-chain acyl-CoA dehydrogenase deficiency in children with non-ketotic hypoglycemia and low carnitine levels. Pediatr. Res. 17:877-884.

5. Rhead, W. J., B. A. Amendt, K. S. Fritchman, and S. J. Felts. 1983. Dicarboxylic aciduria: deficient $\left[1-{ }^{14} \mathrm{C}\right]$ octanoate oxidation and medium-chain acyl-CoA dehydrogenase in fibroblasts. Science (Wash. DC). 221:73-75.

6. Coates, P. M., D. E. Hale, C. A. Stanley, B. E. Corkey, and J. A. Cortner. 1985. Genetic deficiency of medium-chain acyl coenzyme A dehydrogenase: studies in cultured skin fibroblasts and peripheral mononuclear leukocytes. Pediatr. Res. 19:671-676.

7. Divry, P., M. David, N. Gregersen, S. Kolvraa, E. Christensen, J. P. Collet, C. Dellamonica, and J. Cotte. 1983. Dicarboxylic aciduria due to medium chain acyl-CoA dehydrogenase defect. A cause of hypoglycemia in childhood. Acta Paediatr. Scand. 72:943-949.

8. Bougneres, P. F., F. Rocchiccioli, S. Kolvraa, M. Hadchouel, J. Lalau-Keraly, J. L. Chaussain, S. K. Wadman, and N. Gregersen. 1985. Medium-chain acyl-CoA dehydrogenase deficiency in two siblings with a Reye-like syndrome. J. Pediatr. 106:918-921.

9. Howat, A. J., M. J. Bennett, S. Variend, and L. Shaw. 1984. Deficiency of medium chain fatty acylcoenzyme A dehydrogenase presenting as the sudden infant death syndrome. Br. Med. J. 288:976.

10. Duran, M., G. Mitchell, J. B. C. De Klerk, J. P. De Jager, M. Hofkamp, L. Bruinvis, D. Ketting, J. M. Saudubray, and S. K. Wadman. 1985. Octanoic acidemia and octanoylcarnitine excretion with dicarboxylic aciduria due to defective oxidation of medium-chain fatty acids. J. Pediatr. 107:397-404.

11. Roe, C. R., D. S. Millington, D. A. Maltby, T. P. Bohan, S. G. Kahler, and R. A. Chalmers. 1985. Diagnostic and therapeutic implications of medium-chain acylcarnitines in the medium-chain acylCoA dehydrogenase deficiency. Pediatr. Res. 19:459-464.

12. Roe, C. R., D. S. Millington, D. A. Maltby, and P. Kinnebrew. 1986. Recognition of medium-chain acyl-CoA dehydrogenase deficiency in asymptomatic siblings of children dying of sudden infant death or Reye-like syndromes. J. Pediatr. 108:13-18.

13. Amendt, B. A., and W. J. Rhead. 1985. Catalytic defect of medium-chain acyl-coenzyme A dehydrogenase deficiency. Lack of both cofactor responsiveness and biochemical heterogeneity in eight patients. J. Clin. Invest. 76:963-969.

14. Frerman, F. E., and S. I. Goodman. 1985. Deficiency of electron transfer flavoprotein or electron transfer flavoprotein: ubiquinone reductase in glutaric acidemia type II fibroblasts. Proc. Natl. Acad. Sci. USA. 82:4517-4520.

15. Amendt, B. A., and W. J. Rhead. 1986. The multiple acylcoenzyme A dehydrogenation disorders, glutaric aciduria type II, and ethylmalonic-adipic aciduria. Mitochondrial fatty acid oxidation, acyl-coenzyme A dehydrogenase, and electron transfer flavoprotein activities in fibroblasts. J. Clin. Invest. 78:205-213.

16. Ikeda, Y., S. M. Keese, and K. Tanaka. 1986. Biosynthesis of electron transfer flavoprotein in a cell-free system and in cultured human fibroblasts. Defect in the alpha subunit synthesis is a primary lesion in glutaric aciduria type II. J. Clin. Invest. 78:997-1002.

17. Ikeda, Y., K. O. Ikeda, and K. Tanaka. 1985. Purification and characterization of short-chain, medium-chain, and long-chain acyl-
CoA dehydrogenases from rat liver mitochondria. J. Biol. Chem. 260:1311-1325.

18. Finocchiaro, G., M. Ito, and K. Tanaka. 1987. Purification and properties of short chain acyl-CoA, medium chain acyl-CoA, and isovaleryl-CoA dehydrogenases from human liver. J. Biol. Chem. 262:7982-7989.

19. Stanley, C. A., and P. M. Coates. 1985. Inherited defects of fatty acid oxidation which resemble Reye's Syndrome. J. Natl. Reye's Syndrome Foundation. 5:190-200.

20. Turnbull, D. M., K. Bartlett, D. L. Stevens, K. G. M. M. Alberti, G. J. Gibson, M. A. Johnson, A. J. McCulloch, and H. S. A. Sherratt. 1984. Short-chain acyl-CoA dehydrogenase deficiency associated with a lipid-storage myopathy and secondary carnitine deficiency. N. Engl. J. Med. 311:1232-1236.

21. DiDonato, S., F. Cornelio, C. Gellera, D. Peluchetti, M. Rimoldi, and F. Taroni. 1986. Short-chain acyl-CoA dehydrogenase-deficient myopathy with secondary carnitine deficiency. Muscle \& Nerve 9:178. (Abstr.)

22. Amendt, B. A., C. Greene, L. Sweetman, J. Cloherty, V. Shih, A. Moon, L. Teel, and W. J. Rhead. 1987. Short-chain acyl-CoA dehydrogenase deficiency. Clinical and biochemical studies in two patients. J. Clin. Invest. 79:1303-1309.

23. Ikeda, Y., D. E. Hale, S. M. Keese, P. M. Coates, and K. Tanaka. 1986. Biosynthesis of variant medium chain acyl-CoA dehydrogenase in cultured fibroblasts from patients with medium chain acyl-CoA dehydrogenase deficiency. Pediatr. Res. 20:843-847.

24. Treem, W. R., C. A. Witzleben, D. A. Piccoli, C. A. Stanley, D. E. Hale, P. M. Coates, and J. B. Watkins. 1986. Medium-chain and long-chain acyl-CoA dehydrogenase deficiency: clinical, pathologic and ultrastructural differentiation from Reye's syndrome. Hepatology (Baltimore). 6:1270-1278.

25. Frerman, F. E., and S. I. Goodman. 1985. Fluorometric assay of acyl-CoA dehydrogenases in normal and mutant human fibroblasts. Biochem. Med. 33:38-44.

26. Lowry, O. H., N. J. Rosebrough, A. L. Farr, and R. J. Randall. 1951. Protein measurement with the Folin phenol reagent. J. Biol. Chem. 193:265-275.

27. Ikeda, Y., and K. Tanaka. 1987. Immunoprecipitation and electrophoretic analysis of four human acyl-CoA dehydrogenases and electron transfer flavoprotein using antibodies raised against the corresponding rat enzymes. Biochem. Med. Metab. Biol. 37:329-334.

28. Bennett, M. J., R. G. F. Gray, D. M. Isherwood, N. Murphy, and R. J. Pollitt. 1985. The diagnosis and biochemical investigation of a patient with a short chain fatty acid oxidation defect. J. Inher. Metab. Dis. 8(Suppl. 2):135-136.

29. Rebouche, C. J., and A. G. Engel. 1983. Carnitine metabolism and deficiency syndromes. Mayo Clin. Proc. 58:533-540.

30. Carroll, J. E., B. S. McGuire, and C. L. Hall. 1986. Fatty acyl-CoA dehydrogenase enzymes in human skeletal muscle. Clin. Chim. Acta. 161:327-333.

31. Gregersen, N., M. F. Christensen, E. Christensen, and S. Kolvraa. 1986. Riboflavin responsive multiple acyl-CoA dehydrogenation deficiency. Assessment of 3 years of riboflavin treatment. Acta Paediatr. Scand. 75:676-681.

32. Hoppel, C., J. P. DiMarco, and B. Tandler. 1979. Riboflavin and rat hepatic cell structure and function. Mitochondrial oxidative metabolism in deficiency states. J. Biol. Chem. 254:4164-4170.

33. Sakurai, T., S. Miyazawa, S. Furuta, and T. Hashimoto. 1982. Riboflavin deficiency and $\beta$-oxidation systems in rat liver. Lipids. 17:598-604. 